\title{
Editorial
}

\section{Future challenges and opportunities in brand management: An introduction to a commemorative special issue}

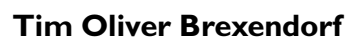 \\ Joachim Kernstock \\ Shaun M. Powell
}

ABSTRACT This commemorative special issue of the Journal of Brand Management has been developed in celebration of $2 I$ years of the Journal. It features seven invited articles from some of the leading thinkers in our field covering a variety of contemporary topics. In this editorial we introduce the seven articles and also delineate five relevant challenges and opportunities to help improve the practical impact of research in our field. It is our hope this timely special issue stimulates the various academic and practitioner brand communities to help orientate future research, while also delivering inspiring ideas for practical implementation in brand management.

Journal of Brand Management (2015) 21, 685-688. doi:10.1057/bm.2015.2

Keywords: brand management; research directions; future research; inspiring ideas

Correspondence: Shaun M. Powell, School of Management, Operations and Marketing, Faculty of Business,

University of Wollongong Australia.

Email: spowell@uow.edu.au

\section{INTRODUCTION}

Within the last two decades research on brand management has accelerated dramatically. Some areas of research are rapidly developing, whereas others are nascent. The last decade has also witnessed a dramatic shift in how brands are consumed and managed with many noting dramatic changes in both managing and studying brands. As a consequence it is an exciting time with growing complexity for brand marketers, practitioners and scholars alike. However, despite these dramatic changes in business practice, brand research in our view has gone through relatively few changes. As noted in the first article of this special issue entitled '21 years of the Journal of Brand Management: A commemorative review', marketing and brand research is sometimes criticised for being far removed from addressing the substantive problems faced by industry. In addition, several high profile practitioners and brand consultancies have expressed the need for organisations to more deeply integrate key stakeholders and customers into their brand management activities. 
We as editors of Journal of Brand Management $(J B M)$ see a dramatically widening gap between ongoing academic discussion and the practical management needs in brand management within the industry. Moving forward, if brand research is not able to impact and reach brand marketers and decision makers in companies and organisations, our entire discipline will weaken its practical relevance and impact in the future. Therefore we have chosen to invite some of the leading brand academics and thinkers in the field, many of whom also consult or advise within industry, to address these new challenges within this special issue.

At a glance the seven articles in this special issue show that the area of brand management is rich, highly varied, and diverse. The diversity of perspectives contained in this special issue is reflected for example by key areas (brand architecture), key constructs (brand experience), and key context (luxury) of brand management. Along with the articles we hope to sketch a landscape of research challenges and opportunities and to suggest where future work could help fill in gaps in our understanding of brand management and strategy.

\section{SPECIAL ISSUE OF THE JOURNAL OF BRAND MANAGEMENT}

In this special issue, seven articles span a range of important topics in our field. The articles address both historical and contemporary issues and phenomena relevant for theory and practice alike, as widely discussed in our discipline in the past few years. Collectively they use valuable approaches and provide us with both perspective and new ideas, while also outlining potential directions for research.

Specifically this special issue addresses:

In the first article, '21 years of the Journal of Brand Management: A commemorative review' Shaun M. Powell on behalf of the $J B M$ Editors looks back on the history of the Journal of Brand Management as well as commenting on its future. His review and analyses also identifies seven key brand management and strategy themes from the Journal archive.

In the second article, 'Designing and implementing brand architecture strategies', Kevin Lane Keller outlines a three-step process by which a firm can design and implement their brand architecture strategy. The architecture of brands is one of the most important brand decisions which also set boundaries. Keller provides a profound but applied approach on how to implement the optimal brand architecture strategy.

In the third article, 'The future of luxury: Challenges and opportunities', Jean-Noel Kapferer focuses attention on how luxury impacts and offers new opportunities for research. He highlights the conceptual use of luxury as business, luxury as a strategy and luxury as a business model. The insight gained can prove to be influential for firms considering either entry or exit in certain categories, depending on their outlook for growth.

In the fourth article, 'The current state and future of brand experience' Bernd $H$. Schmitt, J. Joško Brakus and Lia Zarantonello outline the current state and future scenarios of brand experience. Specifically, they present three research and practical trends, and marketing challenges covering the proliferation of settings and media that evoke brand experiences, the role of brands in consumption experiences and finally the need of brand experiences to reach positive psychological outcomes.

In the fifth article, 'How participation is changing the practice of managing brands', Nicolas Ind argues that branding shifts from an organization-centric view to a participative view where brand marketers are confronted with a connected, dialogic network of all stakeholders. Ind highlights a shift of perspectives from a linear to a social, organic and recursive model of branding where 
managing a brand is more fluid, complex, and of even less control.

In the sixth article, 'The future of brand and brand management - Some provocative propositions from a more methodological perspective', Klaus-Peter Wiedmann focuses his attention on methodology. Wiedmann reflects on the ongoing discussion in our brand discipline around whether new methodologies are needed or not, that is, on positioning or about the link between brand management and corporate leadership. His article offers new perspectives on how to manage brands.

In the seventh article, 'Five areas to advance branding theory and practice', T.C. Melewar and Bang Nguyen insightfully highlight areas that appear widely neglected in current studies plus propose key areas of enquiry for future research in brand management.

To help give an overview, we as $J B M$ Editors can further delineate five relevant challenges and opportunities to help improve the practical impact of research in our field moving forward:

\section{Focus on relevant and substantive topics in brand management}

Brand practitioners pose relevant and important questions to our discipline and also have a role to play in challenging the results academia provides to solve their questions. To provide brand marketers guidance in their daily decisions, it is more and more important to understand the challenges they are facing in their work. Hence greater collaboration between brand practitioners and academic researchers is to be encouraged, as practice poses new and relevant challenges to academia.

\section{Focus on broad contributions in brand management}

As editors in the field we see many articles submitted for consideration for review that offer a lack of contribution. Many submissions tend to empathetically discuss the rigour and robustness of the research, but lack any significant contribution to management issues in brand management. Equally we note that some reviewers focus almost exclusively on the rigour or sophistication of methods - than also consider the actual implication of the findings for industry. Here, our discipline is currently in a permanent trade-off and debate it seems, as also noted in the first article in this special edition that reviews and reflects on the history and heritage of JBM.

\section{Bridging brand understanding and management}

We lose a big portion of our audience as well as our impact, when we lack in wider readability, because of perhaps writing for academic audiences only. In our view as editors, articles written only for an academic audience in brand management and strategy should be the exception and not the rule. Brand management research in its highest level of discussion, still should be applicable to management. If methodology and outcomes remains an academic secret and never gets to market it is useless for brand management practice.

\section{Trade-offs in brand management}

Brand management is the management of trade-offs. Managing strong brands with a long heritage must bridge the permanent trade-off between continuity and innovation to ensure the vitality of the brand. Brand management also needs to consider and bridge the interests of organisations and corporations and their various stakeholders including customers. The pendulum of who is in 'control' of the brand nowadays swings from the firm to the stakeholders. One major impact is that brand managers no longer, if they ever did, fully control the 
messaging they use to create brand strategies. The need to integrate some stakeholders in branding appears to be more the case than ever before. But are all stakeholders or customers interested in becoming involved in brand development? And those that are interested, are they really interested in and contribute to a positive development of the brand? These are only some of the trade-offs brand managers need to manage.

\section{Frameworks and research that provide managerial guidance}

Although a significant body of research in branding has developed over time, knowledge for a number of important topics within the field remains relatively scarce. In addition compared with the beginnings of our discipline, within the last few years very few fresh frameworks have been provided that inform and guide managerial practice. This is especially noticeable where a greater need for brand agility might be needed because of a rapidly changing digital environment.

In summary, the five challenges and opportunities above have provided us with strong motivation for inviting and gathering together the valuable and insightful set of articles that are presented in this special issue of the $J B M$ (Volume 21, Issue 9).

\section{CONCLUSION}

In this special issue we start with a look back on the history and contribution of the $J B M$ and then take stock of the current knowledge and research activity in our field, while reflecting on what might be needed for the future. On the basis of extant research and our views, we have observed that our field requires rethinking, reformulation, and repositioning of some existing ideas and concepts carried over from the last century, but there is also a need for the preservation and optimisation of some proven concepts and strategies. Both directions will ensure the value and relevance of brand management for both theory and practice in the years to come.

We hope this special issue provides new and significant inspiration for brand academics and brand practitioners alike. We also hope it will act as a reminder for the need for relevance, impact and rigour within research in our field. We are aware that not all areas of importance in brand management were mentioned in this collection of articles because of the practical limitations of a special issue. None the less, it is our hope that this issues collection of articles, written by renowned researchers and colleagues in our field, provides an updated and timely roadmap plus fresh food for thought, for avenues and approaches to future research of brands and branding.

There is still much to learn about and contribute to brand management and strategy. We therefore encourage further collaborative and 'innovative' research in the various pillars of our field. We also welcome continued submissions of cutting edge original articles for consideration for publication in $J B M$, and to allow us to hopefully include and celebrate your research in future anniversary edition(s) of this journal with you.

We three editors hope you enjoy and feel stimulated by your reading of the seven articles, as much as we have enjoyed working collaboratively with our many colleagues in the creation of this commemorative special issue, in celebration of 21 years of the JBM.

\section{ACKNOWLEDGEMENTS}

The editors would especially like to thank Justine Hope, Assistant Publishing Editor at Palgrave Macmillan for her encouragement, dedication, diligence and support for this special edition. 